\title{
Effects of the social environment on the
}

survival and fungal resistance of ant brood

\section{Jessica Purcell, Timothée Brütsch \& Michel Chapuisat}

\section{Behavioral Ecology and Sociobiology}

ISSN 0340-5443

Volume 66

Number 3

Behav Ecol Sociobiol (2012) 66:467-474

DOI 10.1007/s00265-011-1293-0

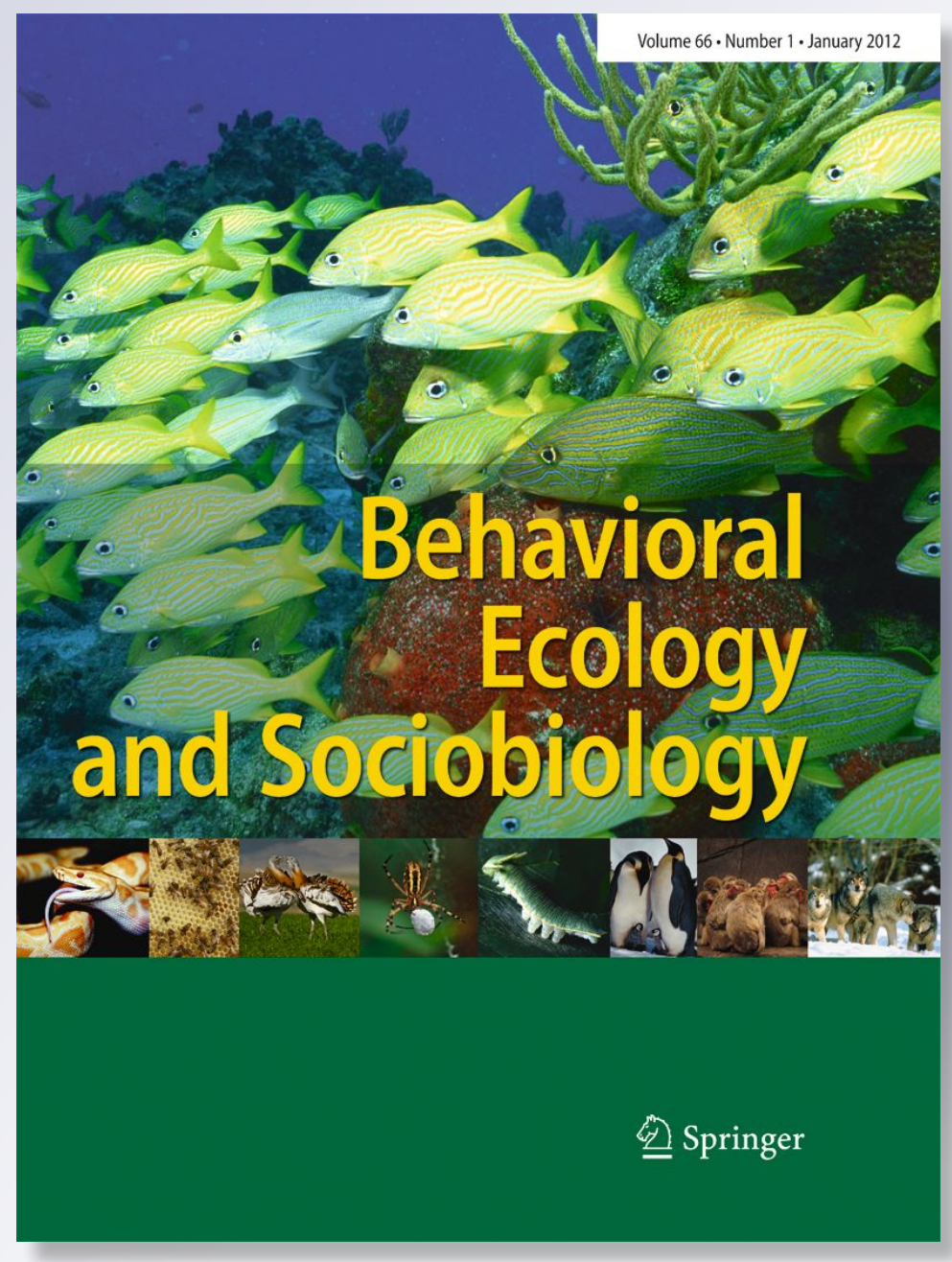

包 Springer 
Your article is protected by copyright and all rights are held exclusively by SpringerVerlag. This e-offprint is for personal use only and shall not be self-archived in electronic repositories. If you wish to self-archive your work, please use the accepted author's version for posting to your own website or your institution's repository. You may further deposit the accepted author's version on a funder's repository at a funder's request, provided it is not made publicly available until 12 months after publication. 


\title{
Effects of the social environment on the survival and fungal resistance of ant brood
}

\author{
Jessica Purcell • Timothée Brütsch • Michel Chapuisat
}

Received: 17 July 2011 /Revised: 10 October 2011 /Accepted: 2 November 2011 / Published online: 25 November 2011

(C) Springer-Verlag 2011

\begin{abstract}
The phenotype of social animals can be influenced by genetic, maternal and environmental effects, which include social interactions during development. In social insects, the social environment and genetic origin of brood can each influence a whole suite of traits, from individual size to caste differentiation. Here, we investigate to which degree the social environment during development affects the survival and fungal resistance of ant brood of known maternal origin. We manipulated one component of the social environment, the worker/brood ratio, of brood originating from single queens of Formica selysi. We monitored the survival of brood and measured the head size and ability to resist the entomopathogenic fungus Beauveria bassiana of the resulting callow workers. The worker/brood ratio and origin of eggs affected the survival and maturation time of the brood and the size of the resulting callow workers. The survival of the callow workers varied greatly according to their origin, both in controls and when challenged with B. bassiana. However, there was no interaction between the fungal challenge and either the worker/brood ratio or origin of eggs, suggesting that these factors did not affect parasite resistance in the conditions tested. Overall, the social conditions during brood rearing and the origin of eggs had a strong impact on brood traits that are important for fitness. We detected a surprisingly large amount of variation among queens in the
\end{abstract}

Communicated by J. Heinze

Electronic supplementary material The online version of this article (doi:10.1007/s00265-011-1293-0) contains supplementary material, which is available to authorized users.

J. Purcell $(\bowtie) \cdot$ T. Brütsch $\cdot$ M. Chapuisat

Department of Ecology and Evolution, Bâtiment Biophore,

Quartier UNIL-Sorge, University of Lausanne,

1015 Lausanne, Switzerland

e-mail: Jessica.Purcell@unil.ch survival of their brood reared in standard queenless conditions, which calls for further studies on genetic, maternal and social effects influencing brood development in the social insects.

Keywords Nature versus nurture $\cdot$ Maternal effect . Parasite resistance $\cdot$ Hymenoptera $\cdot$ Eusociality Polygyny

\section{Introduction}

The relative influence of genotype, maternal effects and rearing environment on the phenotypes of offspring has been the topic of heated debate in humans (e.g., Meaney 2001), and is the subject of ongoing research in a wide range of species (e.g., Soler et al. 2003; Russell and Lummaa 2009; Schwander et al. 2010). Social insects provide an interesting opportunity to investigate these influences. They live in mother-daughter associations within well-defined colonies, which allows for complex social interactions. Egg laying and brood rearing are generally performed by different colony members: the queen and nurse workers, respectively. Thus, the offspring's phenotype is shaped by a combination of factors including the genotype inherited from the parents, maternal effects, as well as indirect genetic effects and environmental effects due to the interactions with its social partners, especially the workers that provide daily care (Brian and Carr 1960; Linksvayer 2006; Kapheim et al. 2011).

Many studies have investigated the mechanisms of caste determination in insect societies. Recent findings suggest that the control of caste differentiation during offspring development can range from predominantly genetic to primarily environmental, with most of the investigated species falling at intermediate points along the continuum (reviewed by Schwander et al. 2010). Within castes, it seems that the genotype, maternal effects and care received 
during development may have some influence on the number of individuals produced (e.g., Linksvayer 2008), their development time (e.g., Howard and Jeanne 2004) and their size (e.g., Schwander et al. 2005; Fournier et al. 2008; Kovacs et al. 2010). The relationships between these inputs remain unclear, and experimental studies manipulating the social environment are needed to better evaluate the respective influence of each factor (Linksvayer and Wade 2005).

The ratio of workers to brood is one element of the social environment that may differ greatly across colonies of different ages and social structures, and that may influence the survival and quality of the brood. In general, most studies have found that a larger worker/brood ratio increases the survival and the size of new workers in a diverse range of ant subfamilies (e.g., Brian 1957; Gray 1971; Wilson 1983; Porter and Tschinkel 1985; Tschinkel 1988), although this benefit may diminish at larger group sizes (Brian 1953). Moreover, workers seem to be unable to properly care for the brood when there are fewer workers than brood (Evesham 1985; Cassill and Tschinkel 1999; Cassill 2002; Hartmann et al. 2003). Little is known about how the worker/brood ratio affects other aspects of offspring quality, such as maturation time and resistance to infection. Recent studies of parasite resistance in social insects indicate that gene by environment interactions are probably important in worker susceptibility (e.g., Reber et al. 2008). Both genetic and environmental factors are known to affect disease resistance in other organisms, including birds (e.g., Saino et al. 1997; Soler et al. 2003), mammals (e.g., Lubach et al. 1995; Prager et al. 2010), and insects (e.g., Cotter et al. 2004; Moreno-Garcia et al. 2010).

In this study, we examined the effect of one component of the social environment, the worker/brood ratio, on the survival and fungal resistance of ant brood of controlled origin. We monitored how brood laid by each queen performed when reared by different numbers of nestmate workers in the ant Formica selysi. In this species, the number of queens varies among colonies (Chapuisat et al. 2004). Each queen usually mates with one male, rarely with two (Chapuisat et al. 2004; Schwander et al. 2005). The number of workers per colony is highly variable, with approximately ten times more workers in colonies headed by multiple queens than in colonies headed by a single queen (Rosset and Chapuisat 2007). Workers from singlequeen (=monogyne) colonies are also significantly larger than workers from multiple-queen (=polygyne) colonies (Schwander et al. 2005) and have a slightly higher activity in one component of the immune system causing bacterial growth inhibition, even when controlling for body size (Castella et al. 2010).

Surprisingly, F. selysi workers originating from polygyne colonies showed a lower survival rate than workers from monogyne colonies when they were experimentally challenged with an entomopathogenic fungus, despite the fact that experimental groups with higher diversity had higher resistance (Reber et al. 2008). This result suggests that, while diversity per se improves the resistance of the group, some other aspect of the polygyne lifestyle reduces the ability of workers to resist infections. The observed difference in parasite resistance might result from variation in immune response (Castella et al. 2010; Vitikainen and Sundström 2011) and/or body size (Schwander et al. 2005). In turn, both factors may be influenced by genetics, maternal effects, and/or social environment experienced during development.

We hypothesize that the ratio of workers to brood might affect the survival and maturation time of brood, as well as the size and parasite resistance of the resulting workers. The direction of the effect is somewhat difficult to predict, and we do not know how the worker/brood ratio varies among field colonies. We do, however, expect the number of workers caring for brood to influence the nutrition, feeding rate, and hygiene of the larvae. In turn, larval nutrition has been shown to strongly influence the immune response of insects (Suwanchaichinda and Paskewitz 1998; Valtonen et al. 2011). Therefore, we expect that a higher worker/brood ratio might result in higher brood survival, with the resulting workers being larger and more resistant to parasites. We simultaneously assessed if brood originating from different mothers varied in survival, maturation time, size and parasite resistance.

\section{Methods}

\section{Brood rearing experiment}

In March-April 2010, we collected 22 ovipositing queens and many workers from a total of 16 polygyne colonies in a large $F$. selysi population located along the Rhône river between Sierre and Susten in Valais, Switzerland $\left(7^{\circ} 36^{\prime} 30^{\prime \prime}\right.$ E, $46^{\circ} 18^{\prime} 30^{\prime \prime} \mathrm{N}$, altitude $565 \mathrm{~m}$ ). In most cases, we collected or at least observed multiple queens in each of these colonies. In the few ambiguous cases, we verified that the colonies were polygynous by genotyping eight workers per colony at eight microsatellite loci (Chapuisat et al. 2004).

In the laboratory, we placed each queen and about 50 workers from her field colony (but no pre-existing brood) in an individual plastic box $(15 \times 13 \times 6 \mathrm{~cm})$ lined with Fluon GP1 (Whitford Plastics, Diez, Germany) to prevent ants from escaping. We supplied water in a glass tube with moist cotton, and covered this tube with a piece of aluminium foil to provide a dark, humid nest. We also provided ad libitum access to standard ant food (Meunier and Chapuisat 2009). The ants were kept at $24 \pm 2{ }^{\circ} \mathrm{C}$ with $50 \%$ humidity under a 
12:12 h light/dark cycle. For 4 weeks (late April through early May), we monitored these boxes regularly and removed newly laid eggs for use in the experiment. At the end of this egg collection period, we measured the heads of the queens using a Leica MZ12.5 microscope (Leica Application Suite 2.8.1) after they were cooled to $10^{\circ} \mathrm{C}$ for about $30 \mathrm{~min}$ to minimize movement. Head size is a good indicator of overall body size (Schwander et al. 2005).

We placed the freshly collected eggs on a small Petri dish, where we observed and counted them under a dissecting microscope. We then divided all of the intact eggs into groups of 20 and placed them on separate Petri dishes. At the same time, we divided the workers from the same field colonies as the eggs into groups of 10, 20, 100, and 200 workers (rearing groups). We placed these groups in large boxes $(38 \times 22 \times 14 \mathrm{~cm})$ with a covered glass water tube, ad libitum access to standard ant food, and fluon lining to prevent escape. In cases when queens had produced enough eggs for each of the four worker/brood ratio treatments (at least 80 eggs), we haphazardly assigned the groups of 20 eggs to each treatment. A total of nine queens produced at least 80 eggs, and 20 queens produced at least 20 eggs. When queens failed to produce enough eggs for a full treatment block, we allocated the groups of 20 eggs in priority to the rearing groups of 20 and 100 workers. With these eggs, we created sixteen 10:20 worker/brood ratio rearing groups with the eggs of 13 queens, twenty 20:20 worker/brood ratio rearing groups with the eggs of 14 queens, twenty-one 100:20 worker/brood ratio rearing groups with the eggs of 16 queens, and sixteen 200:20 worker/brood ratio rearing groups with the eggs of 13 queens.

\section{Brood survival and development}

To start the rearing experiment, we placed the open Petri dishes containing eggs near the entrance to the glass tubes in the boxes with the rearing workers immediately after the eggs were collected and counted. After $48 \mathrm{~h}$, all eggs had been collected and moved to the water tube by workers in 66 out of 73 rearing groups. In the remaining groups, a median of one and a maximum of three eggs were left on the Petri dish, and these groups proceeded with fewer brood. We monitored the number of brood visible, the instar of the brood, and the mortality of workers at least once per week until pupation.

After pupation, we monitored the boxes daily to ensure that we could identify newly emerged callow workers by their light colour. We immediately removed callow workers and placed them in a small plastic box containing ad libitum food and water with two nurses from the same colony, each of which was marked with a small dot of paint on her abdomen. During this period, the mortality rate of callow workers was $6 \%$. For each rearing group, we measured brood survival, calculated as the number of live callow workers that emerged out of 20 eggs, as well as the minimum maturation time of brood for each group that successfully reared new workers, calculated as the number of days between the hatching of the first egg and the emergence of the first callow worker.

\section{Callow survival and fungal challenge}

When the callow workers were 5 days old and fully sclerotized, we exposed them to either the entomopathogenic fungus Beauveria bassiana $\left(10^{8}\right.$ conidia/ml suspended in $0.05 \%$ Tween 20 buffer) or to a control $(0.05 \%$ Tween 20 buffer) by depositing a $2-\mu 1$ droplet directly on the thorax. Previous experiments on $F$. selysi found that, for the $\mathrm{S} 2$ strain of $B$. bassiana that we collected from our field site, this concentration resulted in intermediate mortality rates (Reber and Chapuisat, in press). A similarly high concentration of conidia has also been used in other studies on the response of different insects to B. bassiana (e.g., Castilho et al. 2010; Mukawa et al. 2011). The first callow worker from each rearing group was randomly assigned to either the fungal exposure or the control treatment. Thereafter, we alternated subsequent callow workers emerging from the same rearing group with the fungal exposure and control treatment. In this way, we ensured that callow workers from the same rearing group were evenly represented in both the exposure and the control treatments. We isolated the individuals in small Petri dishes (3.5-cm diameter) containing food and water and monitored their survival daily for 14 days. We removed dead individuals from the Petri dishes, measured their heads, surface sterilized the corpses, and placed them in tubes with wet cotton wool for 30 days to record which corpses produced B. bassiana conidia. At the end of the experiment, we measured the heads of the remaining live workers. Two workers escaped late in the observation period, and five others were mixed up during head measurement. These individuals were excluded from the head size analysis.

\section{Statistical analysis}

We constructed generalized linear models (GLMs) to separate the effect of the worker/brood ratio from the impact of the origin of brood on the survival, maturation time and size of the resulting workers, respectively. In each model, we used the brood measurement as the response variable and the mother identity, worker/brood ratio treatment, as well as the interaction between the two as fixed effects. For the model of callow head size, we used the size of individuals as the response variable, and we nested their rearing group within mother identity to account for any variation among rearing groups. For all of the comparisons in which maternal identity influenced our response variable, we additionally investigated whether 
specific queen traits influenced brood performance. In these GLMs, the response variables were the brood measurements and the fixed effects were maternal (=queen) head size, maternal fecundity, as well as the interaction between the two. For the comparisons wherein the response variable was influenced by worker/brood ratio treatment, we also performed pairwise post-hoc tests to determine which worker/brood ratio treatments differed significantly from one another. For these tests, we used the brood measurement as the response variable, the worker/brood ratio treatment as a fixed effect, and the maternal identity as a random factor. We reported the analysis of deviance and the GLM family (linear for normally distributed data, Poisson for count data, and binomial for binary data) that we used for each comparison. Finally, we used Pearson correlation tests to investigate whether our measures were related to one another.

We investigated how the rearing environment and origin of the brood each influenced the ability of the resulting workers to resist an immune challenge using a parametric

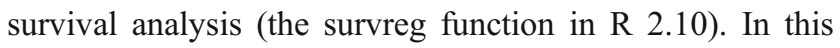
model, the response variable was the number of days that each individual survived after the infection or control solution was administered. This variable was censored when workers survived beyond our observation period, and for the two individuals that escaped during the observation period. The fixed effects included the worker/brood ratio treatment, the maternal identity, the fungal challenge versus control and the interaction terms. We used the Weibull distribution, which produced the minimum error deviance. All statistical analyses were carried out in R 2.10 (R Development Core Team, 2009).

\section{Results}

Brood survival and development

The survival of the brood from the egg stage to the emergence of callow workers was influenced by both the worker/brood ratio during development and the origin of the eggs (Table 1). The relationship between brood survival and worker/brood ratio was nonlinear: the groups of 20 workers provided with 20 eggs exhibited the highest mean number of brood emerging (Fig. 1a) and reared significantly more offspring than the groups of 200 workers (post-hoc comparison, $p=0.0052$ ), but the other pairwise comparisons were not significant after Bonferroni correction $(p=0.023,0.38$ and 0.20 when comparing the worker/brood ratio 10:20 to 20:20, 100:20 and 200:20, respectively; $p=0.029$ and 0.038 when comparing the worker/brood ratio $100: 20$ to $20: 20$ and 200:20, respectively). The maternal origin of eggs greatly influenced brood survival, which ranged from 0 to $29 \%$, with a mean of $6 \%$. This variation in brood survival was not, however, related to the maternal head size or fecundity (Table 2). Queen fecundity varied from 0 to more than 200 eggs produced over the 4 weeks during which we collected their eggs, but this was not correlated with queen size $(r=0.30, p=0.23)$.

The maturation time of brood was influenced by the origin of eggs, as well as the interaction between the origin of eggs and the worker/brood ratio (Table 1). The shortest time from hatching to callow emergence (maturation time) varied greatly among rearing groups, ranging from 20 to 55 days, and eggs from rearing groups with greater worker/brood ratios generally developed faster (Fig. 1b). The variation in maturation time of brood was also linked to an interaction between maternal size and fecundity (Table 2). We found a negative correlation between the number of brood produced and the maturation time $(r=-0.40, p=0.031)$.

The worker/brood ratio and egg origin also had a significant impact on the head size of the resulting workers (Table 1). Brood reared by a greater number of workers were generally larger (Fig. 1c), with groups of 100 workers producing significantly larger workers than groups of 20 workers (post-hoc comparison, $p=0.0067$ ) or 10 workers $(p=0.0004)$ and no differences between rearing groups with 10 and 20 workers $(p=0.51)$. Head size

Table 1 Influence of worker/brood ratio and origin of eggs on brood survival, maturation time, and head size of the resulting callow workers

\begin{tabular}{|c|c|c|c|c|}
\hline \multirow[t]{2}{*}{ Response variable } & \multicolumn{3}{|l|}{ Model factors } & \multirow[t]{2}{*}{ GLM family } \\
\hline & Maternal identity & Worker/brood ratio & Interaction & \\
\hline Brood survival & $\chi^{2}=110.3, d f=15, p<0.0001$ & $\chi^{2}=27.6, d f=3, p<0.0001$ & $\chi^{2}=42.9, d f=33, p=0.12$ & Poisson \\
\hline Maturation time & $F_{13,16}=12.6, p=0.013$ & $F_{3,13}=1.07, p=0.45$ & $F_{9,4}=6.06, p=0.049$ & Linear \\
\hline $\begin{array}{l}\text { Reduced maturation time } \\
\text { (without 200:20) }\end{array}$ & $F_{13,13}=11.4, p=0.015$ & $F_{2,11}=1.16, p=0.40$ & $F_{7,4}=7.77, p=0.033$ & Linear \\
\hline Callow head size & $F_{12,72}=1.98, p=0.017$ & $F_{3,69}=4.84, p=0.005$ & $F_{9,60}=1.57, p=0.15$ & Linear \\
\hline Reduced head size (without 200:20) & $F_{12,68}=2.06, p=0.014$ & $F_{2,66}=6.86, p=0.002$ & $F_{7,59}=1.66, p=0.14$ & Linear \\
\hline
\end{tabular}

For the callow head size comparisons, rearing group identity is nested within maternal identity 

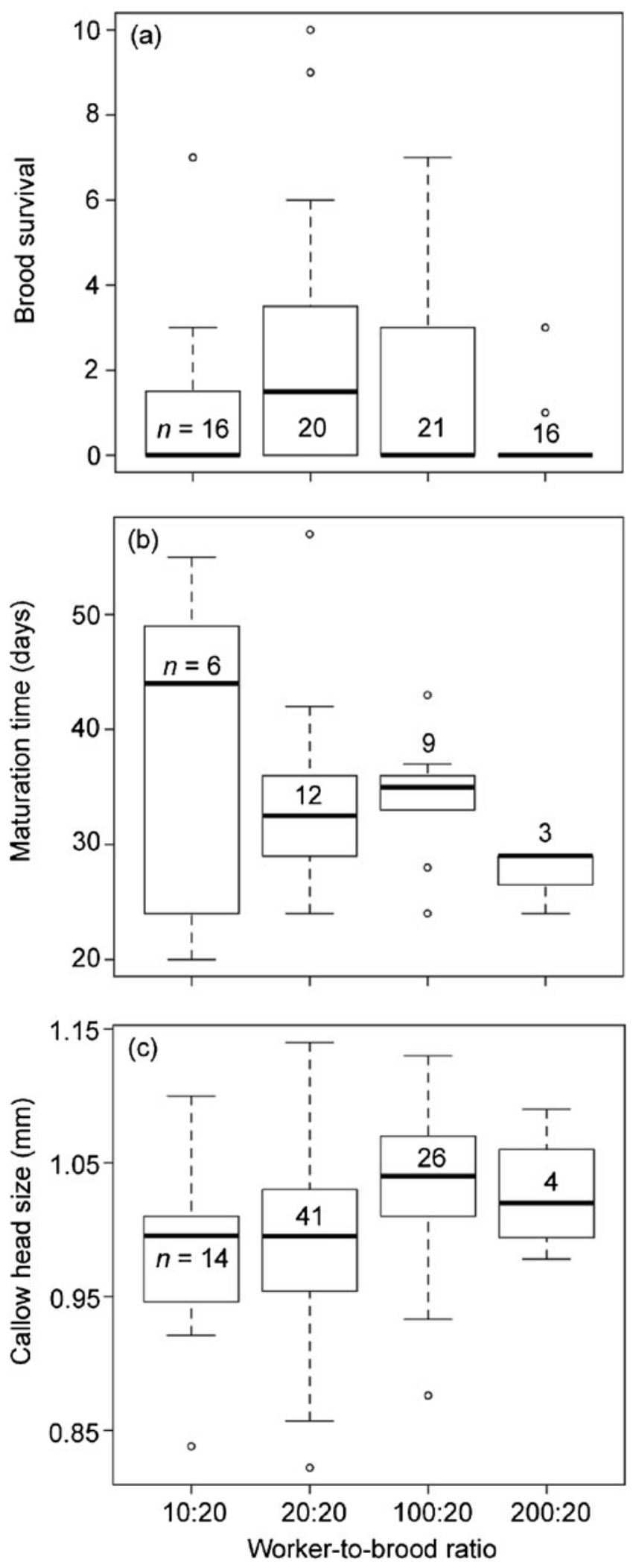

was also weakly heritable from mother to daughter, with maternal head size explaining $5 \%$ of the variance in callow head size (Table 2).
Fig. 1 Effect of the worker/brood ratio on a brood survival, expressed as the number of callow workers emerging out of 20 eggs, b maturation time, expressed as the shortest time from egg hatching to callow emergence in each nest, and $\mathbf{c}$ head size of the resulting callow workers. The boxplots show the median values and the upper and lower quartiles. The whiskers encompass 1.5 times the interquartile range, and the circles represent outliers. The samples sizes for each category (the number of rearing groups in $\mathbf{a}$ and $\mathbf{b}$, and the number of newly emerged workers in c) are shown in each box

Callow survival and fungal challenge

The survival of callow workers was influenced by exposure to $B$. bassiana $\left(\chi^{2}=6.64, d f=1, p=0.010\right)$ and by the origin of the eggs $\left(\chi^{2}=27.26, d f=12, p=0.0071\right)$, but not by the worker/brood ratio $\left(\chi^{2}=3.21, d f=2, p=0.20\right)$ or any of the interactions ( $p>0.4$; full model $\left.\chi^{2}=65.64, d f=87, p=0.11\right)$. Sequential removal of interaction terms did not influence the qualitative results of this analysis; the best fit model contained only the effects of queen and infection status (reduced model $\chi^{2}=36.04, d f=13, p=0.0006$ ). Exposure to the fungal parasite had a negative impact on the survival of callow workers (Fig. 2), and survival was not correlated with the head size of callow workers in our experiment $(r=$ $0.22, p=0.16$ ). In the groups exposed to the parasite, $60 \%$ of the ant corpses yielded B. bassiana conidia, but no conidia were observed on corpses from the control. The worker/brood ratio had no significant effect on the survival of callow workers in the absence of infection, nor on their ability to survive the fungal challenge (Fig. 2). In contrast, the offspring of some mothers had higher survival than others, both when exposed to the fungal parasite and in controls. Hence, the origin of eggs affected the overall survival of callow workers, but did not influence their relative ability to resist the pathogen, as indicated by the lack of interaction between the factors fungal challenge and origin. The overall survival of brood throughout development and during fungal infection thus depended upon worker/brood treatment, maternal origin, and infection status (Appendix 1).

\section{Discussion}

In animals with cooperative brood care, a lot of the phenotypic variability may result not only from genetic variation, but also from the social conditions during development. Here, we examined the impact of one important component of the social environment, the availability of worker nurses, on the development, survival and parasite resistance of brood of known maternal origin. We distributed eggs laid by single ant queens among experimental rearing groups having four worker/brood 
Table 2 Influence of maternal characteristics on brood survival and maturation time, as well as head size and survival rate of the resulting callow workers

\begin{tabular}{lllll}
\hline Response variable & Model factors & & \\
\cline { 2 - 5 } & Maternal head size & Maternal fecundity & Interaction \\
\hline Brood survival & $\chi^{2}=0.55, d f=1, p=0.46$ & $\chi^{2}=0.87, d f=1 p=0.35$ & $\chi^{2}=0.60, d f=1, p=0.44$ & Binomial \\
Maturation time & $F_{1,26}=0.91, p=0.35$ & $F_{1,25=0.34, p=0.57}$ & $F_{1,24}=7.54, p=0.011$ & Linear \\
Callow head size & $F_{1,81}=4.27, p=0.042$ & $F_{1,80}=0.77, p=0.38$ & $F_{1,79}=1.16, p=0.29$ & Linear \\
\hline
\end{tabular}

ratios. In line with previous studies of social insects (e.g., Schwander et al. 2010), we found that the relationship between environmental and parental inputs is complex, with both the social conditions and origin of eggs influencing major traits of the brood. The worker/brood ratio influenced the survival and adult size of the brood. Queens varied greatly in their fecundity during our observation period, as well as in the viability of their brood reared in standard queenless conditions. The callow workers originating from different queens also varied significantly in their post emergence survival. We did not find an impact of either the worker/brood treatment or the maternal origin of eggs on the ability of callow workers to resist the fungal infection.

At the outset, we expected that having more workers available to care for the brood would improve the quality of care. Instead, we found that the worker/brood ratio generally had nonlinear effects on the survival and

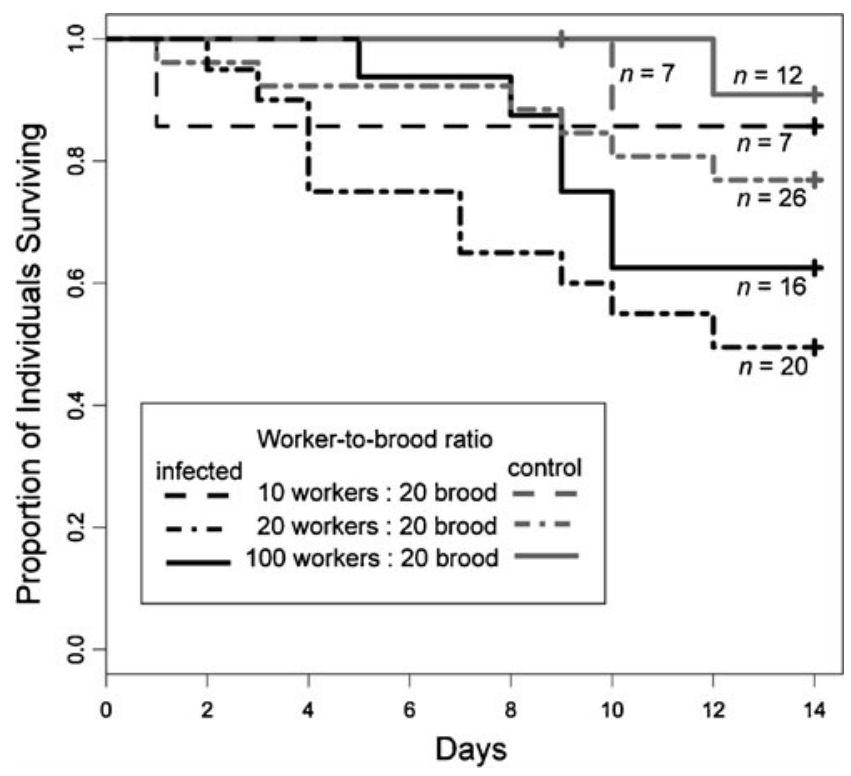

Fig. 2 The proportion of newly emerged workers surviving in controls (gray lines) and when challenged with the entomopathogenic fungus B. bassiana (black lines). The 200:20 worker/brood ratio treatment was omitted from the analysis due to small sample size. The number of individuals from each worker/brood ratio treatment is shown for each category maturation time of brood, as well as on the head size of resulting callow workers. This suggests that there may be developmental trade-offs associated with variation in the worker/brood ratio. For example, when one worker was available to care for each egg (20:20 treatment), the largest number of brood survived, but this brood matured more slowly than the brood reared by a larger number of workers. Some previous studies found a similar trade-off, with larger colony size being associated with a decline in the efficiency of brood care and an increase in the size of workers (reviewed by Tschinkel 1988).

In most of the rearing groups, the workers raised only a small proportion of the eggs until adulthood (Appendix 1). Other experimental studies also had very low brood survival under similar laboratory conditions (e.g., Abril et al. 2010). There are several potential causes for this high rate of attrition. First, the presence of queens in colonies has been found to have a major effect on worker investment in brood in other ant species (e.g., Brian and Carr 1960; Vienne et al. 1998). Second, it is possible that larger groups performed poorly under our laboratory conditions. We housed the colonies in large boxes with ad libitum access to food and water, so we do not believe that crowding per se could have caused this pattern. One source of stress on the brood could have been the higher traffic of adults in and out of the nest tube, where the brood is attended.

Eggs laid by different queens varied greatly with respect to many of the metrics that we measured on the resulting brood, even though the queens were not present in the rearing groups. This variation may have multiple causes. First, the broods differ in their maternal and paternal genotype. Second, they might have been influenced by maternal effects and by environmental or social factors associated with the colony of origin of the queens, including indirect genetic effects through the nestmate workers caring for the brood (Wolf et al. 1998; Linksvayer 2007).

The high variation among queens in both the viability of their immature brood and the resilience of their callow workers is somewhat surprising, as selection should favour queens with high productivity, thereby decreasing genetic variance in reproductive output. A high variation among queens in brood viability has been documented in other 
polygyne species (e.g., Holzer et al. 2006). Moreover, previous studies have found that queens from polygyne colonies varied more in their fecundity than queens from monogyne colonies (e.g., Keller 1988). It is thus possible that selection is somewhat relaxed in colonies with multiple queens. Alternatively, this variation may have no genetic basis. For example, competition among queens might have reduced the reproductive output of some queens (e.g., Keller and Reeve 1994) or there may be differences based on queen age. Finally, queens may also differ in their allocation of reproductive effort toward producing sexual versus worker offspring. It is interesting to note that the same queens that produced a greater number of surviving offspring during this experiment also continued to produce a larger number of callow workers in the laboratory throughout the season (Pearson $r=0.65, p=0.015$ ). Thus it appears that some queens and colonies were consistently more productive than others, at least under laboratory conditions. To better understand the causes of this variation among queens, it would be interesting to quantify the degree of selection on queen fecundity, brood viability and reproductive success in different social contexts (e.g., number of queens present, queen age).

The factors influencing parasite resistance also deserve further investigation. Although both the worker/brood ratio and egg origin influenced some aspects of brood development and offspring quality, we have not yet detected specific factors that contribute to variation in resistance to the fungal parasite $B$. bassiana. Indeed, we found no interaction between the fungal challenge and either the worker/brood ratio or origin of eggs, suggesting that these factors did not affect parasite resistance in the conditions tested. It is, however, likely that there is genetic and social variation for disease resistance (e.g., Hughes and Boomsma 2004; Cremer et al. 2007) and given our sample size, small effects of maternal origin or worker/brood ratio might have remained undetected. There are also many more ways by which social interactions, including grooming or sharing of antibiotics both before and/or during infection, may influence brood and callow immunity (Calleri et al. 2006; Chapuisat et al. 2007; Cremer et al. 2007; Hamilton et al. 2011; Reber et al. 2011). An interesting next step would be to manipulate other aspects of the social or abiotic environment during brood development, and to compare the relative effects of egg origin and social environment on resistance to a variety of naturally occurring pathogens.

Overall, the number of workers available to care for brood is likely to change over the course of the colony life span, and in response to the number of queens in the colony (e.g., Heinze 2008). Our results suggest that the worker/brood ratio plays an important role in the ontogeny of colony characteristics, such as colony growth rate and worker size, which will in turn influence colony success (e.g., Billick 2001; Billick and Carter 2007). Further research is required to identify which factors influence the ability of individual workers to resist fungal infections, and also to determine whether colonies can adjust the worker/brood ratio or brood production strategy in response to the short-term worker requirements of the group.

Acknowledgements We thank Alain Reymond and Dominique Bays for their help with data collection. Thanks also extended to Alan Brelsford and three anonymous reviewers for comments on the manuscript. This study was funded by a Swiss National Science Foundation grant (31003A_125306) to MC.

\section{References}

Abril S, Oliveras J, Crisanto G (2010) Effect of temperature on the development and survival of the Argentine ant, Linepithema humile. J Insect Sci 10:1-13

Billick I (2001) Density dependence and colony growth in the ant species Formica neorufibarbis. J Anim Ecol 70:895-905

Billick I, Carter C (2007) Testing the importance of the distribution of worker sizes to colony performance in the ant species Formica obscuripes Forel. Insect Soc 54:113-117

Brian MV (1953) Brood-rearing in relation to worker number in the ant Myrmica. Physiol Zool 26:355-366

Brian MV (1957) The growth and development of colonies of the ant Myrmica. Insect Soc 4:177-190

Brian MV, Carr CAH (1960) The influence of the queen on brood rearing in ants of the genus Myrmica. J Insect Physiol 5:8194

Calleri DV, Reid EM, Rosengaus RB, Vargo EL, Traniello JFA (2006) Inbreeding and disease resistance in a social insect: effects of heterozygosity on immunocompetence in the termite Zootermopsis angusticollis. Proc R Soc Lond B 273:2633-2640

Cassill D (2002) Brood care strategies by newly mated monogyne Solenopsis invicta (Hymenoptera: Formicidae) queens during colony founding. Ann Entomol Soc Am 95:208-212

Cassill DL, Tschinkel WR (1999) Effects of colony-level attributes on larval feeding in the fire ant, Solenopsis invicta. Insect Soc 46:261-266

Castella G, Christe P, Chapuisat M (2010) Covariation between colony social structure and immune defences of workers in the ant Formica selysi. Insect Soc 57:233-238

Castilho AMC, Fraga ME, Aguiar-Menezes EL, Rosa CAR (2010) Selection of Metarhizium anisopliae and Beauveria bassiana isolates pathogenic to Atta bisphaerica and Atta sexdens rubropilosa soldiers under laboratory conditions. Cienc Rural 40:1243-1249

Chapuisat M, Bocherens S, Rosset H (2004) Variable queen number in ant colonies: no impact on queen turnover, inbreeding, and population genetic differentiation in the ant Formica selysi. Evolution 58:1064-1072

Chapuisat M, Oppliger A, Magliano P, Christe P (2007) Wood ants use resin to protect themselves against pathogens. Proc R Soc Lond B 274:2013-2017

Cotter SC, Kruuk LEB, Wilson K (2004) Costs of resistance: genetic correlations and potential trade-offs in an insect immune system. J Evol Biol 17:421-429

Cremer S, Armitage SAO, Schmid-Hempel P (2007) Social immunity. Curr Biol 17:R693-R702 
Evesham EJM (1985) The interaction of food distribution and the caste composition of an ant colony (Myrmica rubra L.). J Zool 207:241-250

Fournier D, Battaille G, Timmermans I, Aron S (2008) Genetic diversity, worker size polymorphism and division of labour in the polyandrous ant Cataglyphis cursor. Anim Behav 75:151-158

Gray B (1971) A morphometric study of the ant species, Myrmecia dispar (Clark). Insect Soc 18:95-110

Hamilton C, Lejeune BT, Rosengaus RB (2011) Trophallaxis and prophylaxis: social immunity in the carpenter ant Camponotus pennsylvanicus. Biol Lett 7:89-92

Hartmann A, Wantia J, Torres JA, Heinze J (2003) Worker policing without genetic conflicts in a clonal ant. Proc Natl Acad Sci USA 100:12836-12840

Heinze J (2008) Social plasticity: ecology, genetics, and the structure of ant societies. In: Korb J, Heinze J (eds) Ecology of social evolution. Springer-Verlag, Berlin, pp 129-150

Holzer B, Kümmerli R, Keller L, Chapuisat M (2006) Sham nepotism as a result of intrinsic differences in brood viability in ants. Proc R Soc Lond B 273:2049-2052

Howard KJ, Jeanne RL (2004) Rates of brood development in a social wasp: effects of colony size and parasite infection. Insect Soc 51:179-185

Hughes WOH, Boomsma JJ (2004) Genetic diversity and disease resistance in leaf-cutting ant societies. Evolution 58:1251-1260

Kapheim KM, Bernal SP, Smith AR, Nonacs R, Wcislo WT (2011) Support for maternal manipulation of developmental nutrition in a facultatively eusocial bee, Megaloptis genalis (Halictidae). Behav Ecol Sociobiol 65:1179-1190

Keller L (1988) Evolutionary implications of polygyny in the Argentine ant, Iridomyrmex humilis (Mayr) (Hymenoptera: Formicidae): an experimental study. Anim Behav 36:159-165

Keller L, Reeve HK (1994) Partitioning of reproduction in animal societies. Trends Ecol Evol 9:98-102

Kovacs JL, Hoffman EA, Marriner SM, Rekau JA, Goodisman MAD (2010) Environmental and genetic influences on queen and worker body size in the social wasp Vespula maculifrons. Insect Soc 57:53-65

Linksvayer TA (2006) Direct, maternal, and sibsocial genetic effects on individual and colony traits in an ant. Evolution 60:2552-2561

Linksvayer TA (2007) Ant species differences determined by epistasis between brood and worker genomes. PLoS One 2 (10):e994

Linksvayer TA (2008) Queen-worker-brood coadaptation rather than conflict may drive colony resource allocation in the ant Temnothorax curvispinosus. Behav Ecol Sociobiol 62:647-657

Linksvayer TA, Wade MJ (2005) The evolutionary origin and elaboration of sociality in the aculeate Hymenoptera: maternal effects, sib-social effects, and heterochrony. Q Rev Biol 80:317-336

Lubach GR, Coe CL, Ershler WB (1995) Effects of early rearing environment on immune-responses of infant Rhesus monkeys. Brain Behav Immun 9:31-46

Meaney MJ (2001) Nature, nurture, and the disunity of knowledge. Ann NY Acad Sci 935:50-61

Meunier J, Chapuisat M (2009) The determinants of queen size in a socially polymorphic ant. J Evol Biol 22:1906-1913

Moreno-Garcia M, Lanz-Mendoza H, Cordoba-Aguilar A (2010) Genetic variance and genotype-by-environment interaction of immune response in Aedes aegypti (Diptera: Culicidae). J Med Entomol 47:111-120
Mukawa S, Tooyama H, Ikegami T (2011) Influence of humidity on the infection of western flower thrips, Frankliniella occidentalis (Thysanoptera: Thripidae), by Beauverian bassiana. Appl Entomol Zool 46:255-264

Porter SD, Tschinkel WR (1985) Fire ant polymorphism (Hymenoptera: Formicidae): factors affecting worker size. Ann Entomol Soc Am 78:381-386

Prager G, Stefanski V, Hudson R, Roedel HG (2010) Family matters: maternal and litter-size effects on immune parameters in young laboratory rats. Brain Behav Immun 24:1371-1378

Reber A, Chapuisat M (in press) Diversity, prevalence and virulence of fungal entomopathogens in colonies of the ant Formica selysi. Insect Soc

Reber A, Castella G, Christe P, Chapuisat M (2008) Experimentally increased group diversity improves disease resistance in an ant species. Ecol Lett 11:682-689

Reber A, Purcell J, Buechel SD, Buri R, Chapuisat M (2011) The expression and impact of antifungal grooming in ants. J Evol Biol 24:954-964

Rosset H, Chapuisat M (2007) Alternative life-histories in a socially polymorphic ant. Evol Ecol 21:577-588

Russell AF, Lummaa V (2009) Maternal effects in cooperative breeders: from hymenopterans to humans. Philos T R Soc Lond B 364:1143-1167

Saino N, Calza S, Møller AP (1997) Immunocompetence of nestling barn swallows in relation to brood size and parental effort. J Anim Ecol 66:827-836

Schwander T, Rosset H, Chapuisat M (2005) Division of labour and worker size polymorphism in ant colonies: the impact of social and genetic factors. Behav Ecol Sociobiol 59:215221

Schwander T, Lo N, Beekman M, Oldroyd BP, Keller L (2010) Nature versus nurture in social insect caste differentiation. Trends Ecol Evol 25:275-282

Soler JJ, Moreno J, Potti J (2003) Environmental, genetic and maternal components of immunocompetence of nestling pied flycatchers from a cross-fostering study. Evol Ecol Res 5:259-272

Suwanchaichinda C, Paskewitz SM (1998) Effects of larval nutrition, adult body size, and adult temperature on the ability of Anopheles gambiae (Diptera: Culicidae) to melanize sephadex beads. J Med Entomol 35:157-161

Tschinkel WR (1988) Colony growth and the ontogeny of worker polymorphism in the fire ant, Solenopsis invicta. Behav Ecol Sociobiol 22:103-115

Valtonen TM, Roff DA, Rantala MJ (2011) Analysis of the effects of early nutritional environment on inbreeding depression in Drosophila melanogaster. J Evol Biol 24:196-205

Vienne C, Errard C, Lenoir A (1998) Influence of the queen on worker behaviour and queen recognition behaviour in ants. Ethology 104:431-446

Vitikainen E, Sundström L (2011) Inbreeding and caste-specific variation in immune defence in the ant Formica exsecta. Behav Ecol Sociobiol 65:899-907

Wilson EO (1983) Caste and division of labor in leaf-cutter ants (Hymenoptera: Formicidae: Atta): IV. Colony ontogeny of A. cephalotes. Behav Ecol Sociobiol 14:55-60

Wolf JB, Brodie ED III, Cheverud JM, Moore AJ, Wade MJ (1998) Evolutionary consequences of indirect genetic effects. Trends Ecol Evol 13:64-69 